\title{
An analysis of risk assessment questions based on loss-averse preferences
}

\section{Postprint.}

For published article see:

Guillemette, M. A., Yao, R., \& James, R. N. (2015). An analysis of risk assessment questions based on loss-averse preferences. Journal of Financial Counseling and Planning, 26(1), 17-29.

\begin{abstract}
A variety of risk assessment questionnaires are used within the financial planning profession to assess client risk preferences. Evidence indicates that the average person overweighs losses relative to an arbitrary reference point. This paper evaluated risk assessment questions on how well they correlate with monetary loss aversion. Twenty-fine West Texas residents between the ages of 27 and 56 filled out several risk assessment questionnaires and two weeks later their coefficients of loss aversion were measured using monetary gain and loss scenarios. The individual risk assessment questions were placed into three categories: expected utility theory, prospect theory and self-assessment. Composite measures were created for within-group and between-group comparisons. Statistically significant correlations were found between monetary loss aversion and different composite measures. The results provide financial planners with a group of risk assessment questions that capture loss-averse preferences.
\end{abstract}

Keywords: loss aversion, portfolio allocation, questionnaire, risk tolerance, skin conductance response 


\section{Introduction}

A risk assessment questionnaire is often a major input into the financial planning process, helping the planner to better understand the client's preferences and attitudes. Risk assessment can be separated into two parts: objective and subjective risk. Objective risk depends on a person's ability to take risk, and includes factors such as financial wealth, human wealth and labor market flexibility (Hanna, Guillemette \& Finke, 2013). Subjective risk is based on a person's willingness to take risk (Hanna \& Chen, 1997), and is typically measured using a risk assessment questionnaire. Normative economic models assume people treat gains and losses equally. However, the average person has been found to be loss averse (Pennings \& Smidts, 2003; Booij, Van Praag \& Van de Kuilen, 2010), which means they overweigh utility from losses from an arbitrary reference point. Financial planners should help their clients overcome the behavioral bias of loss aversion. This takes time, however, and cannot be accomplished during the initial data gathering stage of the financial planning process when subjective risk assessment occurs. A risk assessment questionnaire that measures a client's tendency to overweight losses relative to comparable gains will help planners to more accurately capture the current risk preferences of these clients.

The expected utility theory (EUT) concept of risk assessment, which is referred to as "risk tolerance," or its inverse, "risk aversion" can be defined as the willingness to accept variation in future consumption. Individuals who are more willing to accept variation in future consumption are more risk tolerant or less risk averse. Individuals with a low level of risk tolerance will prefer a less volatile consumption path over their life span compared to someone who has a greater level of risk tolerance (Modigliani \& Brumberg, 1954). A preference for a less volatile consumption path leads investors to prefer assets whose payout is more certain because 
risk implies a variety of possible future consumption paths (Arrow, 1971; Pratt, 1964). Assets with a lower expected variance of returns are more preferred by investors with a higher coefficient of risk aversion. Risk-averse investors require a greater equity premium to invest in assets where the payout is more uncertain. This insight is fundamental in modern portfolio theory (Markowitz 1952; Sharpe 1964).

The EUT concept of risk assessment implies that the slope of the utility function is the same within gain and loss domains. Evidence indicates that some investors care more about the pain they feel from losses than the satisfaction they derive from gains. Empirical findings have indicated that the average investor is approximately 1.5 to 2.5 times more sensitive to monetary losses than to gains (Tversky \& Kahneman, 1992; Schmidt \& Traub, 2002). Assuming a client is loss averse, both risk tolerance and loss aversion are needed to measure risk preferences. The willingness to accept variation in future consumption (risk tolerance) is essential to measuring client risk preference. However, if a client is loss averse, measuring risk tolerance will not account for the utility derived from losses being different than gains (i.e., risk tolerance does not capture the loss in utility associated with losses compared to gains). Therefore, an assessment of both risk tolerance and loss aversion are needed when the behavioral bias of loss aversion is present.

The behavioral bias of loss aversion can be better attenuated if it is accurately measured. The purpose of this research is to identify risk assessment questions that capture loss-averse preferences. This research question is important as risk assessment questions in the prior literature either measure risk aversion (Hanna, Gutter \& Fan, 2001; Hanna \& Lindamood, 2004) or do not solely measure loss aversion (Grable \& Lytton, 2003; Roszkowski \& Grable, 2005). This exploratory analysis will provide insight into the strength and statistical significance of 
correlations between monetary loss aversion and different types of risk assessment questions. This study should help the financial planning profession move towards a more uniform standard of measuring client risk preferences.

\section{Literature Review}

\section{Risk Assessment Questionnaires}

A variety of questions are included in risk assessment surveys to determine the risk preferences of clients (Chaulk, Johnson \& Bulcroft, 2003; Hartog, Ferrer-I-Carbonell \& Jonker, 2002; Kimball, Sahm \& Shapiro, 2008; Schubert, Brown, Gysler \& Brachinger, 1999). The prior literature has focused on psychometric testing and the validity and reliability of questions when evaluating the quality of risk assessment surveys (Callan \& Johnson, 2002; Grable \& Lytton, 2003; Roszkowski \& Grable, 2005). Psychometric testing of risk assessment questionnaires usually involves an analysis of the consistency of correlations among questions in the survey. Questions that measure a client's self-assessment of their own risk preferences may be useful when developing a risk assessment questionnaire (Roszkowski \& Grable, 2005). Several risk assessment questionnaires already measure the EUT concept of risk tolerance (Barsky, Juster, Kimball, \& Shapiro, 1997; Hanna, Gutter \& Fan, 2001; Hanna \& Lindamood, 2004). However, none of these risk assessment surveys focus on measuring the risk preferences of loss averse individuals.

\section{Loss Aversion: Definition and Measurements}

Prospect theory modified the EUT concept of risk tolerance by overweighting the disutility experienced from losses below an arbitrary reference point. Tversky \& Kahneman (1992) estimated that the marginally decreasing aspect of the value function is 0.88 . People 
overweight losses approximately 2.25 times more than gains based on experimental findings, which means they are loss averse (Tversky \& Kahneman, 1992). Tversky \& Kahneman’s (1992) value function over gains and losses is shown below:

$$
v(X)=\left\{\begin{array}{c}
X^{0.88} \text { for } X \geq 0 . \\
-2.25(-X)^{0.88} \text { for } X<0 .
\end{array}\right.
$$

Prospect theory describes a client's value function as concave in the gain domain and convex in the loss domain. This is referred to as the reflection effect and means that the average client is risk averse within the gain domain and risk seeking within the loss domain (Kahneman \& Tversky, 1979).

Loss aversion has been defined and measured in various ways in the prior literature. Loss aversion was originally defined by $-U(-x)>U(x)$ for all $x>0$ (Kahneman \& Tversky, 1979), which implies that loss aversion should be defined as the mean (or median) of $-U(-x) / U(x)$ over the relevant values of $\mathrm{x}$ (Abdellaoui, Bleichrodt \& Paraschiv, 2007). Tversky and Kahneman (1992) implicitly defined loss aversion as $-U(-\$ 1) / U(\$ 1)$. Benartzi \& Thaler (1995) stated that loss aversion can be estimated by taking the slope of the value function in the loss domain and dividing it by the slope of the value function in the gain domain. Loss aversion has also been measured by estimating, and then comparing, the likelihood of accepting comparable uncertain gambles under both the gain and loss domains (Sokol-Hessner et al., 2009).

Estimating loss aversion by comparing choices to uncertain gains and losses is one way that aversion to losses can be measured. Loss aversion can also be measured by comparing physiological arousal to gains and losses. Measuring physiological response to monetary gains 
and losses increases the validity of a loss aversion measurement if participants respond physiologically to losses more than gains. Skin conductance response (SCR), which is also referred to as electrodermal or galvanic skin response, has been used to estimate physiological arousal to gains and losses (Shiv, Loewenstein, Bechara, Damasio, \& Damasio, 2005; SokolHessner et al., 2009). SCR is measured in units called microsiemens ( $\mu \mathrm{S})$. Latency is the time between the onset of the stimulus (such as a monetary loss) and the beginning of the SCR. The time between the onset of the SCR and its peak amplitude is referred to as rise time and is typically one to three seconds in duration (Figner \& Murphy, 2011). The difference between the onset (baseline) of the SCR and the peak is referred to as the amplitude and is one of the most common SCR measures (Figner \& Murphy, 2011).

\section{Changing Loss Aversion}

There is evidence that loss aversion is not a stable preference. Prior monetary outcomes and cognitive load have been found to alter loss aversion. Researchers have repeatedly found that investors display a "break-even effect", in which they exhibit increased loss aversion in the presence of a prior loss (Sullivan \& Kida, 1995; Thaler \& Johnson, 1990; Weber \& Zuchel, 2005). Researchers have also documented that investors display a "house money effect", in which they exhibit decreased loss aversion in the presence of a prior gain (Ackert, Charupat, Church and Deaves, 2006; Gertner, 1993; Thaler \& Johnson, 1990). The presence of cognitive load reduced the likelihood of risk-neutral choices (Benjamin, Brown and Shapiro, 2013) and temporarily decreased physiological response to small-dollar losses (Guillemette, James \& Larsen, 2014). The amount of effort a financial planner may wish to expend in modifying loss aversion will, of course, depend upon the loss aversion of the individual client. For some clients loss aversion will be a serious behavioral challenge that should be met with dedicated efforts. 
Therefore, measuring loss aversion is useful in many instances. For a smaller subset of clients, loss aversion will be quite minor and should not be a major focus of the planner's time or effort.

\section{Methodology}

\section{Participants}

Twenty-nine individuals participated in this study. Although data from larger samples are always preferred, these are simply not economically feasible in experiments such this one involving the direct monitoring of physiological responses using real money. The use of small samples is common in experimental research (Shiv, et al., 2005; Sokol-Hessner et al., 2009; Dienes \& Seth, 2010) and valuable knowledge can be acquired from these studies. We define a small sample as 70 or less participants. For example, patients with lesions in brain regions that have been linked to emotional decision making make more advantageous economic choices than control participants (Shiv et al., 2005) and framing a series of gambles as a holistic process instead of in isolation has been found to reduce monetary loss aversion (Sokol-Hessner et al., 2009).

The demographic and socioeconomic background of our participants was diverse, as the experimenters wanted an approximate split of male and female participants, as well as a broad age and human capital range. We recruited participants from West Texas through the use of advertisements. Ages ranged from 27 to 56 for the 14 male and 15 female participants. Participants' education levels ranked from less than a high school diploma to earning an advanced degree.

\section{Risk assessment questions}


Two weeks prior to coming in for the experiment participants completed risk assessment questions from FinaMetrica, Grable \& Lytton (2003), Guillemette, Finke and Gilliam (2012), Charles Schwab, Fidelity and two additional miscellaneous questions. All of the risk assessment questions had an ordinal sequence of choices that were mutually exclusive. FinaMetrica's risk profiling system includes questions that are used to measure the EUT concept of risk assessment, which should accurately capture risk preferences in the gain domain, even if loss averse preferences are present. One of the FinaMetrica questions asks clients to choose between a range of more job security and a small pay raise versus less job security and a big pay raise. Another FinaMetrica question asks clients their preference for a range of salaried versus commissionbased pay structures. Guillemette et al. (2012) included a question that proxies for loss averse preferences. The question measured an acceptable level of loss for a client's hypothetical retirement portfolio:

Suppose you have saved \$500,000 for retirement in a diversified stock portfolio. By what percentage could the total value of your retirement assets drop before you would begin to think about selling your investments and going to cash?

1. A $10 \%$ drop (retirement assets drop $\$ 50,000$ to a value of $\$ 450,000$ )

2. A $20 \%$ drop (retirement assets drop $\$ 100,000$ to a value of $\$ 400,000)$

3. A $30 \%$ drop (retirement assets drop $\$ 150,000$ to a value of $\$ 350,000$ )

4. A 40\% drop (retirement assets drop $\$ 200,000$ to a value of $\$ 300,000$ )

5. A $50 \%$ drop (retirement assets drop $\$ 250,000$ to a value of $\$ 250,000$ )

Grable \& Lytton (2003) included two questions in their risk assessment questionnaire to capture the reflection effect:

1. In addition to whatever you own, you have been given $\$ 1,000$. You are now asked to choose between:

a. A sure gain of $\$ 500$

b. A 50 percent chance to gain $\$ 1,000$ and a 50 percent chance to gain nothing

2. In addition to whatever you own, you have been given $\$ 2,000$. You are now asked to choose between: 
a. A sure loss of $\$ 500$

b. A 50 percent chance to lose $\$ 1,000$ and a 50 percent chance to lose nothing

Roskowski \& Grable (2005) analyzed client self-ratings and the question with the most predictive power for risk assessment was:

What degree of risk have you assumed on your investments in the past? (Answer options: $1=$ very small, $2=$ small, $3=$ medium, $4=$ large, $5=$ very large) .

\section{Experimental design}

E-Prime 2.0 (software for computerized experiment design, data collection, and analysis) was used to program and run the experiment on a desktop computer. Each participant was endowed with $\$ 30$ prior to the experiment. Participants were asked to put the money in their pocket or purse as evidence has shown that people place more value on an item that they physically possess compared to an equivalent item they do not possess (Kahneman, Knetsch \& Thaler, 1991). Participants were informed that their $\$ 30$ could go up or down during the experiment and that they could potentially lose their entire endowment. Participants were also informed that they would receive a $\$ 10$ participation fee that was unrelated to their performance when they were finished with the experiment. We would expect that the use of "house money" (the $\$ 40$ total endowment) would result in a reduction in loss aversion. Figure 1 provides an example of the experimental design.

\section{[Insert Figure 1 here]}

SCRs were measured to make sure participants were responding emotionally to the monetary losses more than gains. Participants wore a Q Sensor 2.0 wrist band, developed by Affectiva, an emotional measurement technology company. The sensor captured SCR response every 125 milliseconds. Participants wore the sensor on their left wrist and were asked to type on 
the computer keyboard using their right hand. SCR could not be measured for one participant so they were excluded from the physiological analysis. Once the Q Sensor's calibration was tested, participants were ready to begin the experiment.

On the first screen, participants were asked to memorize a number sequence as cognitive load has been found to alter loss aversion. On the second screen, participants were asked to choose between a certain or uncertain amount of money. The uncertain choice was between two different monetary amounts. Each uncertain amount was assigned a 50\% probability weight. After the selection was made, the monetary outcome was displayed on the third screen for eight seconds in order to allow adequate time to measure participants' SCR to monetary outcomes. Participants were then asked to recall the number sequence on the forth screen to determine whether they were still under cognitive load.

Each participant answered questions under gain-only, loss-only and mixed choices for a total of 312 questions. Figure 1, Slide 2 is an example of a mixed choice question as there is a chance to gain or lose money. For gain-only questions, there was no chance to lose money and for loss-only questions there was no chance to gain money. Monetary values ranged from $-\$ 28$ to $\$ 28$ for each question. Given that house money and break-even effects have been observed in the prior literature, the uncertain monetary choices were systematically ordered so no more than three expected value gain outcomes or three expected value loss outcomes appeared in a row. The order of the questions was the same for every participant. Once the experiment was completed, participants were paid plus or minus half the sum of their outcomes, as every question was asked twice. Participants were also paid the $\$ 10$ participation fee. Due to institutional review board guidelines, participants could not owe the experimenter money.

\section{Loss aversion equations}


Equation 1 displays the model used to derive the coefficient of loss aversion $(\lambda)$ for each participant.

\section{Equation 1. Loss aversion model}

$$
A R=\text { gain } * \beta 1+\text { loss } * \beta 2+\text { certainty } * B 3+P M O * \beta 4+H C L * \beta 5+e
$$

The formula shown in Equation 1 was used with the 312 questions for each participant. Whether the participant accepted or rejected (AR) the uncertain monetary choice is coded as one or zero, respectively, and is the dependent variable. In Figure 1, Slide 2, the uncertain monetary choice is option B. Analysis of variance and analysis of covariance assume the error terms are normality distributed so these methods of analysis were not selected. A logistic regression model is appropriate to examine the relation in Equation 1 between a binary dependent variable and a number of independent variables (Davidson \& MacKinnon, 2004). The regression coefficients are estimated using maximum likelihood estimation. A logistic regression model assumes a linear value function and the value function under prospect theory has been shown to be approximately linear using small gambles (Rabin, 2000).

The continuous independent variables in Equation 1 include the gain of the uncertain monetary choice, the loss of the uncertain monetary choice, the certain outcome, the previous monetary outcome (PMO) and whether the participant was under high cognitive load (HCL). In order for a risk averse participant to select the uncertain monetary choice its expected value should be greater than the certain monetary choice (Arrow, 1971; Pratt, 1964). An example of the gain of the uncertain monetary choice would be the $\$ 15$ in Figure 1, Slide 2. The hypothesized direction of effect would be positive as participants should be more likely to accept the uncertain monetary choice as the gain of the uncertain monetary choice increases. An example of the loss of the uncertain monetary choice would be the $-\$ 10$ in Figure 1 , Slide 2 . As 
the loss of the uncertain monetary choice becomes less negative we would expect participants to be more likely to accept the gamble. The $\$ 0$ choice in Figure 1, Slide 2 would be an example of a certain outcome. The hypothesized direction of effect for the certain monetary outcome would be negative. As the certain monetary outcome increases participants should be less likely to accept the uncertain monetary choice. House money and break-even effects were controlled for by including the PMO the participant observed in the prior question. For example, if the participant observed a value of $\$ 20$ prior to observing the outcome of $-\$ 10$ in Figure 1 , Slide 3, then $\$ 20$ would be included as the PMO. The PMO should be positively associated with choosing the uncertain monetary choice as prior gains have been found to increase the willingness to take risk.

HCL was included in the model to control for the effect of cognitive load.

Equation 2 shows how $\lambda$ was derived from Equation 1.

\section{Equation 2. Derivation of the coefficient of loss aversion}

$$
\lambda=-\beta \text { loss / Bgain }
$$

$\lambda$ was derived by taking the negative beta for the loss of the uncertain monetary choice and dividing it by the beta for the gain of the uncertain monetary choice for each participant. We hypothesize that the beta coefficient for losses will be greater than the beta coefficient for gains, on average, based on prior experimental research. If the beta coefficient for losses is greater than the beta coefficient for gains it means that a participant is loss averse.

Equation 3 displays the model used to analyze participant's physiological arousal to absolute and relative gains and losses.

\section{Equation 3. Physiological response to absolute and relative gains and losses}

$$
A M P=A L R L * \beta 1+A G R G * B 2+A G R L * B 3+e
$$


This model is important because it tells us whether participants were responding emotionally to the gains and losses and also whether they responded to the losses more than the gains. The SCR amplitude (AMP) variable is the dependent variable and is created by taking the SCR at the onset of the stimulus and subtracting it from the maximum SCR value up to 6000 milliseconds later. In Figure 1, AMP is measured from the time at which Slide $3(-\$ 10)$ appears on the computer screen until six seconds later. All AMP values are non-negative numbers. The AMP variable was square root-transformed to reduce skewness. The distribution of the AMP variable contains a high number of zero values as $28.82 \%$ of questions resulted in a $\mu \mathrm{S}$ reading of zero. When the dependent variable contains a large number of zero values the use of an ordinary least squares model is not appropriate as regression coefficients will be biased (Maddala, 1987). A Tobit model is used as this type of model produces data similar to the AMP variable data.

In order to determine whether participants were responding physiologically to monetary gains and losses, dummy variables were created for absolute gains and losses. If a participant observed a non-negative outcome the absolute gain variable (AG) was coded as one and the absolute loss variable (AL) was coded as zero. According to prospect theory, individuals place a greater emphasis on relative gains and losses compared to absolute gains and losses. To account for relative gains and losses the certain outcome was subtracted from the observed outcome to create a relative gain/loss variable. If the relative gain/loss was greater than zero the relative gain variable $(R G)$ was coded as one, otherwise the relative loss variable $(R L)$ was coded as one. For example, suppose the certain outcome was $\$ 5$ and the uncertain outcomes were $\$ 15$ and - $\$ 5$. If the participant chose the uncertain outcome and observed $\$ 15$ the RG would be $\$ 10$, since the opportunity cost was $\$ 5$. 
Variables were created to account for both absolute and relative gains and losses. If a participant was exposed to an absolute loss and a relative loss the absolute loss-relative loss variable (ALRL) was coded as one. If a participant experienced an absolute gain and a relative gain the absolute gain-relative gain variable (AGRG) was coded as one. If an absolute gain and a relative loss were observed the absolute gain-relative loss variable (AGRL) was coded as one. No outcome was both an absolute loss and a relative gain. Choosing the certain outcome was used as the reference group. Based on prior experimental findings we hypothesize that the SCR to ALRL will be greater than the response to AGRG. If the participant experiences an AGRL we hypothesize that they will be conflicted and not consistently register a SCR reading.

\section{Correlation between loss aversion and risk assessment questions}

A variety of correlation statistics (e.g., Pearson's correlation coefficient $r_{p}$, Spearman's rank correlation $r_{s}$, and Kendall's $\tau$-parameters) were possible choices to determine the relation between $\lambda$ and the risk assessment questions. Pearson's correlation measures the strength of a linear relation between two variables and requires the data to be normally distributed. The data collected in this study did not meet the linearity and normality assumptions, and were ranked scales, which called for non-parametric correlation statistics.

Spearman's rank correlation is similar to Pearson's correlation in that its square term measures the proportion of the variability in one variable that is accounted for by the variability of another variable. However, because the variables examined in this study were ranks, it is difficult to make meaningful interpretations based on the variance of these ranks. In contrast, Kendall's $\tau$-parameters measures a probability, which is the difference between the probability that the observed data are in the same order (i.e., concordant) versus the probability that the observed data are not in the same order (i.e., discordant). This interpretation is more 
straightforward than Spearman's rank correlation. According to Kendall \& Gibbons (1990), confidence intervals for Kendall's $\tau$-parameters are more reliable than confidence intervals for Spearman's $r_{S}$, which is a biased statistic in an analysis with small samples and usually underestimates the population value (Cliff, 1996). For the above reasons, Kendall's $\tau$-parameters were used for this study. Kendall's $\tau$-parameter was used to test whether loss aversion rank and risk assessment questions were statistically dependent. A $\tau$-parameter test is non-parametric and therefore does not rely on any assumptions on the distribution of X (loss aversion rank) or Y (the risk assessment questions). The null hypothesis of a $\tau$-parameter test is that $\mathrm{X}$ and $\mathrm{Y}$ are statistically independent.

In order to establish the efficacy of the risk assessment questions, questions from different surveys were sorted by the theory from which they most closely aligned using a Delphi method. The three categories included EUT (five questions), prospect theory (five questions) and self-assessment (five questions). Internal consistency was measured for each of the three categories and a minimum threshold of 0.5 was set for Cronbach's alpha based on prior literature (Tillmann \& Silcock, 1997; Robb \& Woodyard, 2011). Cronbach's alphas for the EUT, prospect theory and self-assessment categories were $0.61,0.56$ and 0.73 , respectively. Every possible question combination was summed within each of the three categories. The within-group composite measures with the highest Kendall's $\tau_{\mathrm{b}}$ correlation coefficients were then selected from each category. Finally, all 15 questions were pooled in order to determine the betweengroup composite measure with the highest Kendall's $\tau_{\mathrm{b}}$ correlation coefficient. The Cronbach's alpha for the between-group composite measure was 0.53 . 


\section{Results}

The distribution of $\lambda$ is provided in Table 1.Ten participants were risk seeking, three were gain-loss neutral and sixteen were loss averse. Sokol-Hessner et al. (2009) reported similar results when measuring loss-averse preferences.

\section{[Insert Table 1 here]}

Physiological response to gains and losses are reported in Table 2. The coefficient for the ALRL variable is approximately two times greater than the coefficient for the AGRG variable. Physiologically, SCR AMP is twice as strong for losses compared to gains. This is consistent with the finding that the dissatisfaction experienced from losses is approximately two times greater than the satisfaction derived from comparable gains. The AGRL variable is not statistically significant, which suggests that when participants experienced an absolute gain, but a relative loss, they were conflicted and did not consistently register a SCR.

[Insert Table 2 here]

The questions that were selected for each of the three within-group composite measures are displayed in Table 3. Kendall's $\tau_{\mathrm{b}}$ correlation coefficients are reported for each individual question. For the EUT category, the questions with the highest Kendall's $\tau_{\mathrm{b}}$ correlation coefficients with the loss aversion rank included choosing between job security and a pay raise, and a sure gain and an uncertain gain. The prospect theory questions focused on choosing an acceptable loss level for an investment, asking what comes to mind first when someone thinks of the word "risk," and the likelihood of selling a dividend-paying stock that is down $30 \%$ this year. 
The self-assessment questions asked about current insurance coverage, how your best friend would describe you as a risk taker and recent investment changes.

$$
\text { [Insert Table } 3 \text { here] }
$$

Kendall's $\tau_{\mathrm{b}}$ correlation coefficients for the within-group composite measures are reported in Table 4 . There is a marginal benefit for every composite measure over using any single question within each category. All of the within-group composite measures are statistically significant.

[Insert Table 4 here]

Table 5 displays the summation of between-group questions that resulted in the highest correlation with loss aversion rank $\left(\tau_{\mathrm{b}}=0.4793 ; p<.01\right)$. The five-question between-group composite measure provides a $29.79 \%$ marginal benefit from the self-assessment within-group composite measure.

[Insert Table 5 here]

\section{Conclusions}

The purpose of this research was to identify risk assessment questions that capture lossaverse preferences. Participants answered risk assessment questions from different surveys. The questions were separated into three categories: expected utility theory, prospect theory and selfassessment. Participants' levels of loss aversion were measured using small-dollar gains and losses. On average, participants' physiologically responded to losses more than comparable gains. Kendall Tau correlations were analyzed between individuals' levels of loss aversion and their responses to the risk assessment questions. The composite risk assessment measures with the highest correlation with loss aversion were captured to help improve risk assessment instruments. 
The results of this study should help the financial planning profession move towards a uniform standard of client risk assessment. There was a $15 \%$ marginal benefit when moving from the prospect theory composite measure to the self-assessment composite measure. However, at least one question from all three of the categories was included in the final composite measure that had the highest correlation with loss aversion. While self-assessment questions may provide a benefit over solely using expected utility or prospect theory questions, all three categories of questions are useful when assessing client risk preferences.

\section{Implications for Financial Planners}

Financial planners should help clients overcome the behavioral bias of loss aversion and make rational investment decisions. However, subjective risk assessment typically occurs during the early stages of the planner-client relationship before a financial planner has had time to attenuate their clients' loss-averse tendencies. This study provides financial planners with risk assessment questions that can help measure loss aversion without extensive lab experiments. Questions that ask clients about their willingness to accept variation in income and their current insurance coverage are useful when measuring loss aversion. Asking clients about the likelihood of selling a dividend-paying stock that has declined significantly in value and their actual behavior regarding recent investment changes may also be helpful when constructing a risk assessment questionnaire. Finally, whether clients focus on the words "opportunity or thrill" or "uncertainty or loss" when they think of the word "risk" may be useful when constructing a risk assessment survey.

\section{Limitations and Directions for Future Research}


Limitations of this study include the use of small monetary amounts, a small sample size, and the use of house money. The use of small amounts of money is a limitation as participants risk preferences might have been different had larger amounts been used. A larger sample size would reduce uncertainty about the unknown parameters in the models. The use of house money, as opposed to using the participants' money is another limitation as a mental accounting effect has been found in the prior literature. The house money effect would predict that risk taking would increase since participants could not owe the experimenter money.

Future research should utilize the method provided by this study to test risk assessment questions with a larger sample size in order to measure the reliability of the questions. Future research should also test additional risk assessment questions to determine how well they correlate with monetary loss aversion. Risk assessment scores should be scientifically linked to an optimal asset allocation strategy, which should be the ultimate goal of measuring client risk preferences. 


\section{References}

Abdellaoui, M., Bleichrodt, H., \& Paraschiv, C. (2007). Loss aversion under prospect theory: A parameter-free measurement. Management Science, 53(10), 1659-1674.

Ackert, L. F., Charupat, N., Church, B. K., \& Deaves, R. (2006). An experimental examination of the house money effect in a multi-period setting. Experimental Economics, 9(1), 5-16.

Arrow, K. J. (1971). Essays in the theory of risk-bearing (Vol. 1). Chicago: Markham Publishing Company.

Barsky, R. B., Juster, F. T., Kimball, M. S., \& Shapiro, M. D. (1997). Preference parameters and behavioral heterogeneity: An experimental approach in the health and retirement study. Quarterly Journal of Economics, 112(2), 537-579.

Benartzi, S., \& Thaler, R. H. (1995). Myopic loss aversion and the equity premium puzzle. Quarterly Journal of Economics, 110(1), 73-92.

Benjamin, D. J., Brown, S. A., \& Shapiro, J. M. (2013). Who is 'behavioral'? Cognitive ability and anomalous preferences. Journal of the European Economic Association, 11(6), 1231 1255.

Booij, A. S., Van Praag, B. M., \& Van de Kuilen, G. (2010). A parametric analysis of prospect theory's functionals for the general population. Theory and Decision, 68(1-2), 115-148.

Callan, V. J., \& Johnson, M. (2002). Some guidelines for financial planners in measuring and Advising clients about their levels of risk tolerance. Journal of Personal Finance, 1(1), 31 44.

Chaulk, B., Johnson, P. J., \& Bulcroft, R. (2003). Effects of marriage and children on financial risk tolerance: A synthesis of family development and prospect theory. Journal of Family and Economic Issues, 24(3), 257-279. 
Cliff, N. (1996). Answering ordinal questions with ordinal data using ordinal statistics. Multivariate Behavioral Research, 31(3), 331-350.

Davidson, R., \& MacKinnon, J. G. (2004). Econometric Theory and Methods (Vol. 21). New York: Oxford University Press.

Dienes, Z., \& Seth, A. (2010). Gambling on the unconscious: A comparison of wagering and confidence ratings as measures of awareness in an artificial grammar task. Consciousness and Cognition, 19(2), 674-681.

Figner, B., \& Murphy, R. O. (2011). Using skin conductance in judgment and decision making research. A handbook of process tracing methods for decision research, 163-184.

Gertner, R. (1993). Game shows and economic behavior: Risk-taking on "Card Sharks". Quarterly Journal of Economics, 108(2), 507-521.

Grable, J. E., \& Lytton, R. H. (2003). The development of a risk assessment instrument: A follow-up study. Financial Services Review, 12(3), 257-274.

Guillemette, M. A., Finke, M., \& Gilliam, J. (2012). Risk Tolerance Questions to Best Determine Client Portfolio Allocation Preferences. Journal of Financial Planning, 25(5), 36-44.

Guillemette, M., James, R., \& Larsen, J. (2014). Loss aversion under cognitive load. Journal of Personal Finance. Forthcoming.

Hanna, S., \& Chen, P. (1997). Subjective and objective risk tolerance: Implications for optimal portfolios. Financial Counseling and Planning, 8(2), 17-26.

Hanna, S. D., Guillemette, M. A., \& Finke, M. S. (2013). Assessing Risk Tolerance. In H. Kent Baker and Greg Filbeck (Eds.), Portfolio Theory and Management (99-120). New York: Oxford University Press.

Hanna, S. D., Gutter, M. S., \& Fan, J. X. (2001). A measure of risk tolerance based on economic 
theory. Journal of Financial Counseling and Planning, 12(2), 53-60.

Hanna, S., \& Lindamood, S. (2004). An improved measure of risk aversion. Journal of Financial Counseling and Planning, 15(2), 27-45.

Hartog, J., Ferrer-I-Carbonell, A., \& Jonker, N. (2002). Linking measured risk aversion to individual characteristics. Kyklos, 55(1), 3-26.

Kahneman, D., Knetsch, J. L., \& Thaler, R. H. (1991). Anomalies: The endowment effect, loss aversion, and status quo bias. Journal of Economic Perspectives, 193-206.

Kahneman, D., \& Tversky, A. (1979). Prospect theory: An analysis of decision under risk. Econometrica, 263-291.

Kendall, M., \& Gibbons, J. D. (1990). Rank Correlation Methods. Edward Arnold: London.

Kimball, M. S., Sahm, C. R., \& Shapiro, M. D. (2008). Imputing risk tolerance from survey responses. Journal of the American Statistical Association, 103(483), 1028-1038.

Maddala, G. S. (1987). Limited dependent variable models using panel data. Journal of Human Resources, 307-338.

Markowitz, H. (1952). Portfolio Selection. Journal of Finance 7(1), 77-91.

Modigliani, F., \& Brumberg, R. (1954). Utility analysis and the consumption function: An interpretation of cross-section data. In Kenneth K. Kurihara (Ed.), Post Keynesian Economics. New Brunswick: Rutgers University Press.

Pennings, J. M., \& Smidts, A. (2003). The shape of utility functions and organizational behavior. Management Science, 49(9), 1251-1263.

Pratt, J. W. (1964). Risk aversion in the small and in the large. Econometrica, 122-136.

Rabin, M. (2000). Risk aversion and expected-utility theory: A calibration theorem. Econometrica, 68(5), 1281-1292. 
Robb, C. A., \& Woodyard, A. S. (2011). Financial Knowledge and Best Practice

Behavior. Journal of Financial Counseling \& Planning, 22(1), 60-70.

Roszkowski, M., \& Grable, J. (2005). Estimating risk tolerance: The degree of accuracy and the paramorphic representations of the estimate. Journal of Financial Counseling and Planning, 16(2), 29-47.

Schmidt, U., \& Traub, S. (2002). An experimental test of loss aversion. Journal of Risk and Uncertainty, 25(3), 233-249.

Schubert, R., Brown, M., Gysler, M., \& Brachinger, H. W. (1999). Financial decision-making: Are women really more risk-averse? American Economic Review, 89(2), 381-385.

Sharpe, W. (1964). Capital Asset Prices: A Theory of Market Equilibrium Under Conditions of Risk. Journal of Finance, 19(3), 425-442.

Shiv, B., Loewenstein, G., Bechara, A., Damasio, H., \& Damasio, A. R. (2005). Investment behavior and the negative side of emotion. Psychological Science, 16(6), 435-439.

Sokol-Hessner, P., Hsu, M., Curley, N. G., Delgado, M. R., Camerer, C. F., \& Phelps, E. A. (2009). Thinking like a trader selectively reduces individuals' loss aversion. Proceedings of the National Academy of Sciences, 106(13), 5035-5040.

Sullivan, K., \& Kida, T. (1995). The Effect of Multiple Reference Points and Prior Gains and Losses on Managers' Risky Decision Making. Organizational Behavior and Human Decision Processes, 64(1), 76-83.

Thaler, R. H., \& Johnson, E. J. (1990). Gambling with the house money and trying to break even: The effects of prior outcomes on risky choice. Management Science, 36(6), 643-660. Tillmann, M., \& Silcock, J. (1997). A comparison of smokers' and ex-smokers' health-related quality of life. Journal of Public Health, 19(3), 268-273. 
Tversky, A., \& Kahneman, D. (1992). Advances in prospect theory: Cumulative representation of uncertainty. Journal of Risk and Uncertainty, 5(4), 297-323.

Weber, M., \& Zuchel, H. (2005). How do prior outcomes affect risk attitude? Comparing escalation of commitment and the house-money effect. Decision Analysis, 2(1), 30-43. 


\begin{abstract}
About the authors
Michael A. Guillemette, Ph.D., CFP® is an assistant professor in the Personal Financial Planning Department at the University of Missouri. His research focuses on risk assessment and the demand for insurance. Michael received a B.B.A. in Risk Management \& Insurance, and a B.S. in Education from the University of Georgia. He earned a master's degree and Ph.D. in Personal Financial Planning from Texas Tech University. Michael currently serves on the board for the Society of Financial Service Professionals in Columbia, Missouri.
\end{abstract}

Rui Yao, Ph.D., CFP ${ }^{\circledR}$, is an associate professor and Director of Graduate Studies in the Personal Financial Planning Department at the University of Missouri. Dr. Yao received her doctoral degree from Ohio State University. Her research interests focus on helping individuals and households increase financial well-being and, specifically, their retirement preparation, financial risk tolerance, investment behavior, saving motives, debt management, and consumption patterns. She received the best paper award from the CFP Board, AARP, and American Association of Family \& Consumer Sciences. Dr. Yao serves on the editorial board and as a reviewer for a number of academic journals and conferences. She has been committed to working with the China Center for Financial Research in Tsinghua University of China and is a member of the research team on their first national survey of Chinese Consumer Finance and Investor Education.

Russell James, J.D., Ph.D., CFP® is a professor in the Department of Personal Financial Planning at Texas Tech University. He holds the $\mathrm{CH}$ Foundation Chair in Personal Financial Planning and directs the on-campus and online graduate program in Charitable Financial Planning. His research focuses on uncovering practical and neuro-cognitive methods to encourage generosity and satisfaction in financial decision-making. He graduated, cum laude, from the University of Missouri School of Law where he was a member of the Missouri Law Review. He also received a Ph.D. in Consumer \& Family Economics from the University of Missouri, where his dissertation was on charitable giving. 


\section{Tables}

Table 1. $\lambda$ quantiles

\begin{tabular}{cc}
\hline Quantile & $\boldsymbol{\lambda}$ \\
\hline $\mathbf{2 5 \%}$ & 0.7989 \\
Median & 1.1461 \\
$\mathbf{7 5 \%}$ & 1.5535 \\
\hline
\end{tabular}

Table 2. Physiological response to absolute and relative gains and losses

\begin{tabular}{llll}
\hline Variable & Estimate $(\boldsymbol{\mu S})$ & $\begin{array}{l}\text { Standard } \\
\text { Error }\end{array}$ & t-Value \\
\hline Intercept & $0.0928^{* *}$ & 0.0031 & 29.85 \\
ALRL & $0.0200^{* *}$ & 0.0055 & 3.63 \\
AGRG & $0.0104^{*}$ & 0.0052 & 2.00 \\
AGRL & 0.0002 & 0.0129 & 0.01 \\
\hline
\end{tabular}

$* p<.05$ alpha level;

$* * p<.01$ alpha level 
Table 3. Composition of within-group composite measures

\begin{tabular}{|c|c|c|}
\hline Category & Description of Questions & Kendall's $\tau_{b}$ \\
\hline \multirow[t]{2}{*}{ EUT } & $\begin{array}{l}\text { FinaMetrica - Question } 5 \\
\text { This question asks clients their preference for job security } \\
\text { versus a pay raise. The five choices range from definitely } \\
\text { more job security with a small pay raise to definitely less job } \\
\text { security with a big pay raise. }\end{array}$ & $0.3495^{*}$ \\
\hline & $\begin{array}{l}\text { Grable and Lytton (2003) - Question } 9 \\
\text { In addition to whatever you own, you have been given } \\
\$ 1,000 \text {. You are now asked to choose between: } \\
\text { a. A sure gain of } \$ 500 \text {. } \\
\text { b. A } 50 \% \text { chance to gain } \$ 1,000 \text { and a } 50 \% \text { chance to gain } \\
\text { nothing. }\end{array}$ & 0.2271 \\
\hline \multirow[t]{3}{*}{ Prospect Theory } & $\begin{array}{l}\text { FinaMetrica - Question } 17 \\
\text { This question tells clients that they are considering putting } \\
25 \% \text { of their investment funds in one investment that does } \\
\text { not protect principle and pays approximately double the rate } \\
\text { of a certificate of deposit (CD). The question then asks the } \\
\text { client how low the chance of loss would have to be in order } \\
\text { for them to make the investment. The four responses range } \\
\text { from zero chance of loss to a } 50 \% \text { chance of loss. }\end{array}$ & 0.2740 \\
\hline & $\begin{array}{l}\text { Fidelity - Question } 3 \\
\text { This question asks what loss level on an original investment } \\
\text { is generally acceptable. It then provides five acceptable loss } \\
\text { levels that range from zero percent (with the potential for } \\
\text { negative real returns) to more than thirty percent. }\end{array}$ & 0.2432 \\
\hline & $\begin{array}{l}\text { Grable and Lytton (2003) - Question } 6 \\
\text { When you think of the word "risk" which of the following } \\
\text { words comes to mind first? } \\
\text { a. Loss } \\
\text { b. Uncertainty } \\
\text { c. Opportunity } \\
\text { d. Thrill }\end{array}$ & 0.2003 \\
\hline
\end{tabular}


Miscellaneous - Question 2

Suppose you have owned a stock for several years that has a long-run expected annual return of $8 \%$, but $4 \%$ was from appreciation, and you had received a check every quarter that made up the other 4\%. If the market, and your stock, was down $30 \%$ this year but the quarterly dividend checks were continuing as before, how likely would you be to sell it?

a. I would definitely sell the stock

b. I would probably sell the stock

c. I would probably not sell the stock

d. I would definitely not sell the stock

Self-Assessment FinaMetrica - Question 24

This question asks clients how much insurance coverage they have in the following domains: theft, fire, accident, illness and death. The four choices range from very little to complete coverage.

Grable and Lytton (2003) - Question 1

In general, how would your best friend describe you as a risk taker?

a. A real gambler

0.2044

b. Willing to take risks after completing adequate research

c. Cautious

d. A real risk avoider

FinaMetrica - Question 19

This question asks clients how their personal investments have changed in recent years. The five responses range from always toward lower risk to always toward higher risk.

$* p<.05$ alpha level;

$* * p<.01$ alpha level

Table 4. Correlation between within-group composite measures and $\lambda$ rank

\begin{tabular}{ll}
\hline \multicolumn{1}{c}{ Category } & \multicolumn{1}{c}{ Kendall's $\tau_{\mathrm{b}}$} \\
\hline EUT & $0.3564^{*}$ \\
Prospect Theory & $0.3211^{*}$ \\
Self-Assessment & $0.3693^{* *}$ \\
\hline$* p<.05$ alpha level; \\
$* * p<.01$ alpha level
\end{tabular}


Table 5. Composition of between-group composite measure

\section{Description of Questions}

Kendall's $\tau_{b}$

FinaMetrica - Question 5

$0.3495^{*}$

This question asks clients their preference for job security versus a pay raise. The five choices range from definitely more job security with a small pay raise to definitely less job security with a big pay raise.

FinaMetrica - Question $24 \quad 0.3039^{*}$

This question asks clients how much insurance coverage they have in the following domains: theft, fire, accident, illness and death. The four choices range from very little to complete coverage.

\begin{tabular}{ll}
\hline FinaMetrica-Question 19 & 0.2039
\end{tabular}

This question asks clients how their personal investments have changed in recent years. The five responses range from always toward lower risk to always toward higher risk.

Grable and Lytton (2003) - Question 6

0.2003

When you think of the word "risk" which of the following words comes to mind first?

a. Loss

b. Uncertainty

c. Opportunity

d. Thrill

Miscellaneous - Question 2

0.1343

Suppose you have owned a stock for several years that has a long-run expected annual return of $8 \%$, but $4 \%$ was from appreciation, and you had received a check every quarter that made up the other $4 \%$. If the market, and your stock, was down $30 \%$ this year but the quarterly dividend checks were continuing as before, how likely would you be to sell it?

a. I would definitely sell the stock

b. I would probably sell the stock

c. I would probably not sell the stock

d. I would definitely not sell the stock

$* p<.05$ alpha level;

$* * p<.01$ alpha level 


\section{Figures}

Source: Kahneman and Tversky (1979)

Figure 1. Experimental design example

\section{Slide 1}

Remember this number sequence in the order it is displayed:

Press the SPACE BAR to continue.

\section{$\underline{\text { Slide } 2}$}

Using the keyboard, select which option you prefer.
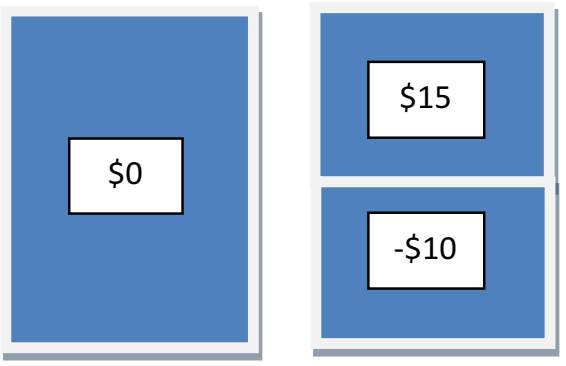

$$
\mathrm{A}=\text { certain } \quad \mathrm{B}=50 / 50
$$

$\underline{\text { Slide } 3}$

$-\$ 10$

$\underline{\text { Slide } 4}$

Type the last number sequence you were asked to remember in the order it was displayed. 
Press the SPACE BAR to proceed to the next screen. 